\title{
Estimation of $\operatorname{IgM}$ rheumatoid factors by fluorimetry
}

\author{
D. J. LEA AND D. J. WARD \\ From the Department of Rheumatology, Robert Jones and Agnes Hunt Orthopaedic Hospital, Oswestry, \\ Salop SY10 7AG
}

SUMMARY Sheep red cells coated with rabbit IgG antibody may be used to detect IgM rheumatoid factors either by agglutination or microscopically by the fluorescence of antihuman IgM antibody conjugate bound to rheumatoid factors on the cell surface. By substituting for red cells the plastic surface of a filter disc coated with rabbit IgG it was possible to elute the bound conjugate and measure the fluorescence in a fluorimeter. The results of both the sheep cell agglutination test and the fluorescence test agreed quite well for the majority of sera; both tests seemed to reflect IgM rheumatoid factor concentrations in these sera. The difficulties encountered in attempting to define and measure accurately rheumatoid factor concentrations in a serum are emphasised.

The sensitivity and apparent simplicity of agglutination tests make them deservedly popular for the detection of abnormal levels of antibody. The clinical specificity of the sheep cell agglutination test (SCAT) renders it a valuable diagnostic aid, despite the fact that only high molecular weight IgM rheumatoid factors (RFs) are detected and the reagents are labile and difficult to standardise. Rabbit IgG bound to a hydrophobic latex gives agglutination titres with RFs which are related to SCAT titres (Grieble et al., 1969; Bach and Schmidt, 1972; Marcolongo and Saletti, 1974).

Following the procedure described by Estes $e t$ al. (1973), Hettenkofer and Muller (1975) used fluorescent antiglobulin reagents to titrate RFs bound to rabbit IgG-coated sheep cells microscopically and were able to distinguish between SCAT positive and SCAT negative sera. Since elution of antibodies from a plastic surface, using detergent (Salmon et al., 1969), is easily achieved we therefore adapted the microscopic fluorescence titration procedure to measure, in a conventional fluorimeter, labelled antihuman IgM antibody bound to a plastic surface bearing RF-rabbit IgG complexes.

\section{Materials}

Sera were obtained from patients attending clinics or admitted to the rheumatology ward and were stored immediately at $-20^{\circ} \mathrm{C}$. SCAT tests were performed within a few days and fluorescence tests within a few weeks whenever possible. Fluoresceinlabelled antisera prepared by Dakopatts A/S were

Accepted for publication September 14, 1977

Correspondence to Dr D. J. Lea obtained from Mercia Diagnostics Ltd. Rabbit Cohn FII and Tween 20 were supplied by Koch-Light Ltd. Chemicals of analytical grade were used when available. Polypropylene discs, $9 \mathrm{~mm}$ in diameter were punched from $P$ \& S no. 12 filter cloth (kindly donated by $\mathbf{P} \& \mathbf{S}$ Textiles Ltd, Haslingden, Rawtenstall, Lancs.). $2 \cdot 5 \mathrm{ml}$ flat-bottomed autoanalysis cups were used as containers.

Stock borate saline buffer (Kotoulas and Moroz' 1971) containing $0 \cdot 15 \mathrm{M}$ sodium chloride and $0 \cdot 15$ $\mathrm{M}$ boric acid was adjusted to $\mathrm{pH} 8.6$ with sodium hydroxide and used as a $10 \%$ solution. Stock

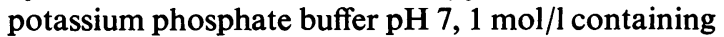
sodium azide $(2 \mathrm{~g} / \mathrm{l})$ was diluted to $0 \cdot 1 \mathrm{~mol} / \mathrm{l}$ for use and Tween $20(0.05 \%)$ was added to reduce nonspecific binding effects (Engvall and Perlmann, 1972). A stock solution $(10 \mathrm{mg} / \mathrm{ml})$ of rabbit FII in phosphate buffer was prepared and filtered for use. It was stored at $-20^{\circ} \mathrm{C}$. Alkaline sodium dodecyl sulphate (SDS) was prepared using $2 \mathrm{~g} / 100 \mathrm{ml} 0 \cdot 1$ $\mathrm{N} \mathrm{NaOH}$.

\section{Method}

Using a $1 \mathrm{~cm}$ diameter quartz cell in a Locarte digital fluorimeter with 13 stage PM tube and zinc lamp, the optimum sensitivity was achieved with a primary filter combination $805 \mathrm{Q}$ (Ilford) and BG $12 / 2 \mathrm{~mm}$ (Schott) and secondary filters $805 \mathrm{Q}$, OG $515 / 2 \mathrm{~mm}$, and Wratten 55 (Kodak). The instrument response was linear, turbidity interference minimal, and stability within experiments and between days high after a few minutes' warm-up.

After treatment with ethanol and hot $40 \%$ caustic soda solution, the plastic discs were rinsed 
thoroughly and packed loosely into a plastic tube. The discs were mixed with rabbit FII solution $(2 \mu \mathrm{l}$ per disc) in borate saline $(30 \mu \mathrm{l}$ per disc) for about 6 hours at room temperature. Each batch of 40 to 60 discs was rinsed, washed overnight in Tween phosphate buffer $(50-100 \mathrm{ml})$, rinsed, and drained. The patient's serum under investigation, diluted with Tween phosphate buffer to $100 \mu l$, was added to a new autoanalysis cup and an FII-coated disc was put in, avoiding bubbles. The racks containing these cups were shaken gently, covered, and kept at room temperature for about 6 hours. Each disc was washed three times by filling the cup with Tween phosphate buffer and draining.

From a freshly prepared solution of anti-IgM conjugate and filtered normal rabbit serum in buffer $(10 \mu \mathrm{l}$ and $40 \mu \mathrm{l}$ respectively in $1 \mathrm{ml})$ a portion of $100 \mu \mathrm{l}$ was added to each cup and disc, and after gentle agitation the covered racks were kept overnight at room temperature. Three washes removed excess conjugate and bound conjugate was dissolved by adding $1 \mathrm{ml}$ alkaline SDS solution to each cup. Fluorescence values of the eluates were read in an instrument standardised at 1.000 with $1 \mathrm{ml}$ SDS solution containing a $5 \mu \mathrm{l}$ portion of conjugate/serum in buffer, using a blank of SDS solution.

\section{Results}

Several variables of the assay procedure were examined. Dilute conjugate in Tween phosphate buffer lost activity slowly and therefore all protein solutions were diluted immediately before use to reduce the effect of denaturation in the assay. No significant fading of fluorescence of SDS solutions was detected after exposure for 30 minutes in the fluorimeter or after standing for 2 hours at room temperature. No more conjugate could be recovered from discs after SDS treatment. FII-coated discs bound approximately $0 \cdot 1 \%$ of the conjugate under assay conditions and coated discs saturated with RFs about $5 \%$ of the conjugate. Substitution of $1 \%$ crystalline bovine plasma albumin for Tween 20 gave only a marginal improvement in these values.

Six coated discs were saturated with RFs by identical treatment with one serum in large excess. Treatment in the same assay with two anti-IgM conjugates standardised by the manufacturer but with different batch numbers gave different mean fluorescence values. Such variability is a characteristic of antisera to multivalent antigens. The amount of conjugate eluted from a disc is therefore not an exact measure of the amount of IgM bound to the disc.

Incubation for at least 5 hours with antibody at each stage was required for the highest sensitivity.
Equal amounts of conjugate were bound by R coated discs rinsed three times or washed for 8 houts and loss of antibody from discs was therefore neghgible. Fluorescence measurements showed that in the assay saturation of discs with RFs occurred at sert商 volumes of about $2 \mu \mathrm{l}$ or more. The volunf fluorescence curves were, as expected, nonline Sera gave different plateau values of fluorescenge, indicating that the RFs bound were probably not all of the IgM class, although IgM molecules differ in the amount of conjugate they can bind (de Bruyn and Klein, 1976). The maximum amount of conjugare bound represented about $5 \mathrm{ng}$ human IgM bound fo $_{0}$ a disc.

After $1 \mu l$ samples of serum (titre 128) were treated with one, two, or three coated discs, IgM RFs weipe readily detectable in all the supernatants. The total amount of RF bound to a disc was therefore dependent upon the affinity as well as the overall concentration of RFs in the serum.

When a variety of solid absorbents, includiang polystyrene tubes, were tested the plastic filter dişs gave better precision. One serum sample gave $\$ 00$ replicate values with a standard deviation of $4^{\circ} \%$ of the mean value in one experiment. However, the lower precision achieved in routine assays madesit necessary to use three replicate discs for every serwion dilution. Volumetric errors in the preparation off dilutions were insignificant. The complexity of the assay system meant that a simple correction factor could not apply to results from different experimenț.

Five SCAT-positive sera were assayed at one le $(0 \cdot 8 \mu \mathrm{l})$ for IgG RFs, by using fluorescent anti-IgG conjugate, and gave fluorescence values between 0.77 and 0.355 , which seemed unrelated to their SCAT titres. Similar serum samples heated at $56^{\circ} \mathrm{C}$ for $\overline{\exists 5}$ minutes gave consistently higher values, 0.256 go 0.583 . There was no way of deciding which of the two procedures gave a better measure of IgG Rds in these sera. In contrast, no effect of heating the sera was evident when anti-IgM conjugate was used.

From the manufacturer's data sheet on the fluorescein conjugate $100 \mu \mathrm{g}$ IgM precipitates $1 \mathrm{ml}-\mathrm{Of}$ fluorescent antiserum under test conditions. In the assay, therefore, $5 \mathrm{ng}$ IgM RF would bind conjug represented by a fluorescence value of $1 \cdot 0$, with considering mass action and steric effects, and contribution of low MW IgM RFs. Our fluorescense values of 0.4 to 1.0 which are commonly given $6 y$ seropositive sera therefore represent the binding of 2 to $5 \mathrm{ng}$ conjugate, values similar to those repored by Hay et al. (1975). Because our absorption resufts suggest that the major proportion of RFs in a ser $\overrightarrow{\mathrm{g} m}$ remain in solution under assay conditions it seems likely that seropositive sera frequently have IgM $\mathrm{KF}$ 
concentrations greatly in excess of $5 \mu \mathrm{g} / \mathrm{ml}$, considering rabbit-specific RFs only.

A series of SCAT-positive and SCAT-negative sera from patients and normal individuals were assayed at a sample volume of $1 \mu \mathrm{l}$. The results of two experiments are shown in Figs. 1 and 2. Each experiment was composed of determinations done on several days. Within each experiment no significant change in sensitivity occurred, as shown by reassaying each day four representative sera. An unexpected combination of high fluorescence value and low SCAT titre was given by serum from a patient with myeloma and mixed connective tissue disease. Although the determination of both fluorescence values and SCAT titres were subject to experimental error, it was evident that a relationship existed between the titre of a serum and the amount of IgM in $1 \mu \mathrm{l}$ serum, which was bound to immobilised rabbit IgG under assay conditions.

By constructing a standard curve using one standard serum at different volumes the fluorescence values for test sera at a fixed volume $(0 \cdot 8 \mu \mathrm{l})$ could be expressed in terms of the equivalent volume of standard determined at the same time. This approach was found inadequate as few sera could be examined in each experiment.

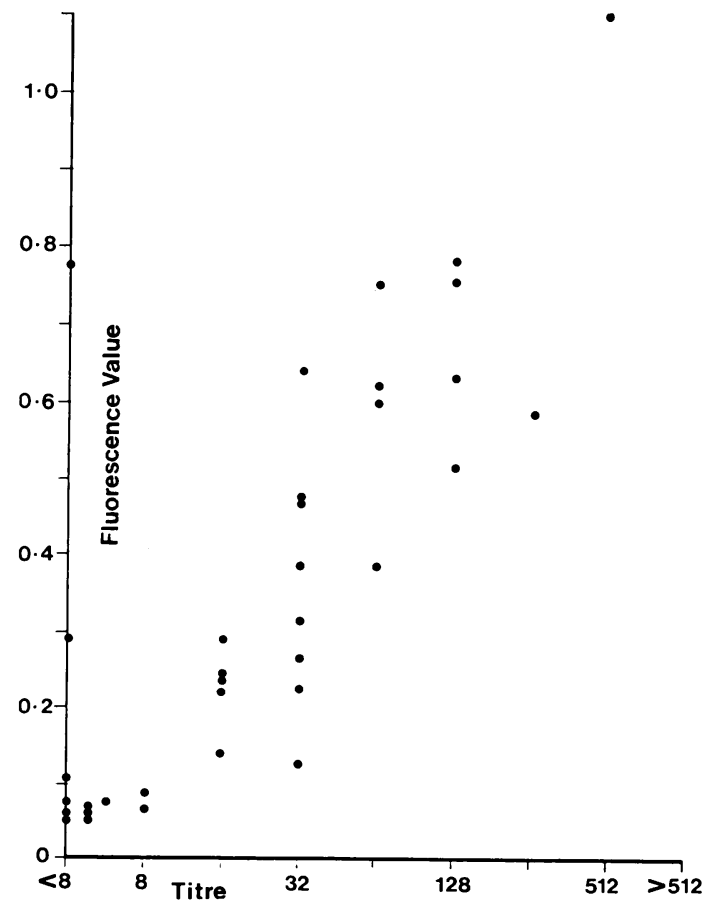

Fig. 1
In order to use a purified, stable rabbit IgG antigen in place of Cohn fraction II, ovalbumin-coated discs were treated with rabbit antiovalbumin serum. Both antibody treated and ovalbumin control discs bound negligible amounts of fluorescent antihuman IgM conjugate under the usual assay conditions. The fluorescence values for two human sera were $0 \cdot 1$ and 0.3 with the ovalbumin-coated control discs, suggesting that these sera contained sufficient antiovalbumin antibodies to interfere with the RF assay.

\section{Discussion}

The SCAT and related red cell and latex tests are the only ones generally available for the demonstration of RFs. The disadvantage of these agglutination tests are well known and many attempts have been made to introduce new, quantitative tests which are claimed to be specific, accurate, and clinically valuable. Whereas immunoassay techniques for determining the concentration of homogeneous antigens and simple chemicals may be judged in terms of specificity, accuracy, and precision, greater problems arise in the measurement of heterogeneous antigens, such as parathyroid hormone and serum immunoglobulins. Highly selective antisera

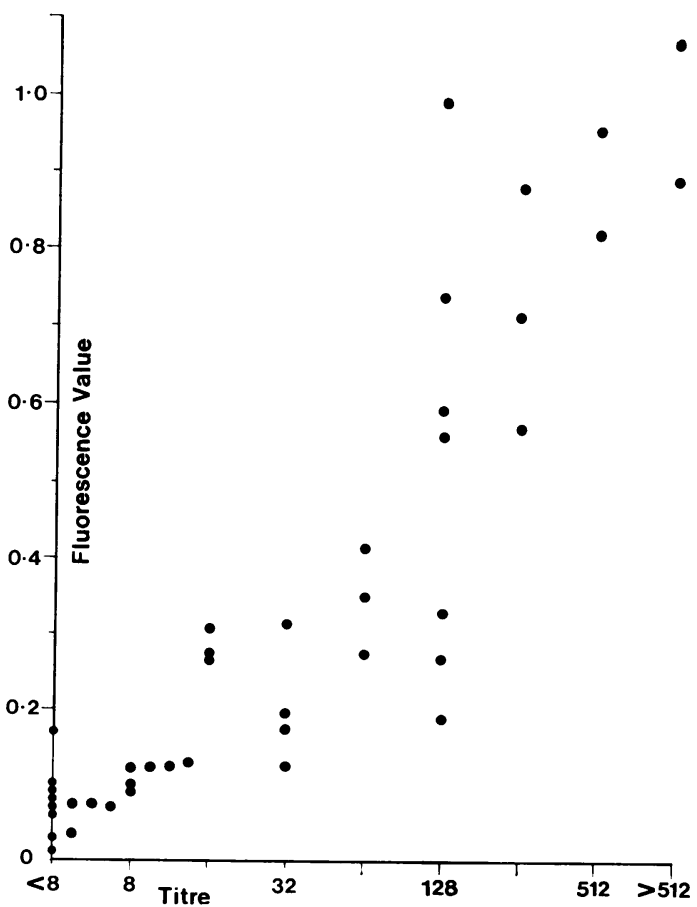

Fig. 2

Figs. 1 and 2 show the results of experiments 1 and 2 respectively. Both show the SCAT titres of sera and their IgM fluorescence values determined at one concentration. 
are required (Grubb, 1973; Lea and Ward, 1975) and the results may not be quantitative, though clinically of value (Schmidt-Gayk et al., 1976).

The quantitation of antibody presents similar problems. The antibody population in an antiserum raised to a specific antigen is rarely homogeneous, and antibodies of all immunoglobulin classes may be present. The antigen may have many different determinants, each with its own specific antibody population and antibodies of low affinity may be present in large amounts (Kim et al., 1974). Even the simplest approach to the quantitation of one antibody (IgE) in a serum requires several measurements to be made to take account of the equilibrium between free antibody and that bound to allergen (Bongrand et al., 1976). The amount of one antibody bound to an insoluble antigen is thus influenced by the experimental conditions chosen and is not determined solely by the total amount present.

Clinical observations suggest that the SCAT test provides the most useful evidence for the presence of IgM RFs in a serum. We have made a basic assumption that the titre of a serum reflects closely the concentration of those IgM RFs able to react with rabbit IgG determinants on the sheep cell surface. Moreover our results could not be judged by any independent criterion other than SCAT titres. On this stated basis the evident relationship between SCAT titre and fluorescence value, measured by our technique, leads us to believe that the fluorescence value of a serum is also a satisfactory index of IgM RF concentration.

Norberg (1976) emphasised that independent evidence is needed to prove valid any assay procedure which purports to reflect IgG RF concentrations. Lacking such evidence we were unable to decide if either of the fluorescence assay procedures using heated or unheated serum samples and anti-IgG conjugate provided a satisfactory index of IgG RF concentrations.

Compared to the radioimmunoassay technique described by Hay et al. (1975) and Nineham et al. (1976), the technique we developed has several advantages. In the radioimmunoassay $50 \mu \mathrm{l}$ of patient's serum in a total volume of $0.5 \mathrm{ml}$ was used. As only $1 \mu \mathrm{l}$ serum in $100 \mu \mathrm{l}$ total volume is required for the fluorescence assay, the interference by dissociable immune complexes (Abruzzo and Heimer, 1974 ) is reduced. Our choice of longer reaction times likewise not only increased sensitivity, with a reduction in serum concentration, but also allowed equilibrium to be approached.

For routine purposes the preparation and purification of radiolabelled antibody is tedious and demanding. Not only are the techniques for the critical testing of specificity well established for fluorescent antisera (Chantler and Haire, 19:72) but the availability of these antisera fractionated before and after labelling reduces the differences between assays arising solely from differerees between conjugate preparations. It is importan $\underline{\text { thto }}$ note that techniques using labelled antihuman $\mathrm{Ig}$ antibody do not distinguish between human agglutinating high MW IgM antibodies and the næonagglutinating IgM antibodies of low MW.

Addition of unlabelled normal rabbit serum to.the fluorescent conjugate was essential to reduce negnspecific binding and the unwanted specific binding of labelled rabbit IgG as antigen to the bound RFFon the plastic discs. These precautions may account:for the much lower background uptake of conjugate by plastic discs than was found, for example, in ithe fluorescence assay of Cukor et al. (1976) who usfed cyanogen bromide-treated paper loaded with poden allergen.

In conclusion, we suggest that the flourescence test provides an alternative method to the sheep $\overline{\text { sell }}$ agglutination test for assaying sera containing rabbitspecific IgM RFs, the results of the two tests c\&lnparing quite well. The values obtained are influenced by the equilibrium between bound and free RFs the test cannot be quantitative, as chemical esti tions are, but the technique does seem to be valid. In its present form it still suffers from the disadvan of day-to-day variability, common to many 'so phase' tests, but appears to be better in this respect than the SCAT test. A major cause of this variab is probably the low affinity of RFs for rabbit IgG. Fluorescence tests of a similar kind may be sạtisfactory alternatives to many latex agglutination tests and to others using radiolabelled or enzyme-labeiled reagents.

\section{References}

Abruzzo, J. L., and Heimer, R. (1974). The measurement of IgG anti-IgG antibody in rheumatoid arthritis. Journa of Immunological Methods, 4, 149-160.

Bach, G., and Schmidt, J. (1972). Studies on the Donspecificity of rheumatoid factor determination. Zeitscifift für Immunitätsforschung, 144, 42-48.

Bongrand, P., Vervloet, D., Depieds, R., and Charpin, J. (1976). What can be measured with RAST? Journdig of Immunological Methods, 11, 197-212.

Chantler, S., and Haire, M. (1972). Evaluation of Che immunological specificity of fluorescein-labelled human IgM conjugates. Immunology, 23, 7-12.

Cukor, P.. Woehler, M. E., Persiani, C., and Fermin $A$. (1976). Iodinated versus fluorescent labelling in the radioallergosorbent test (RAST) for the determination of serum IgE levels. Journal of Immunological Methods, 12, 183-792.

deBruyn, A. M., and Klein, F. (1976). The validity ofthe radial immunodiffusion method for the quantitifive determination of human IgM. Evaluation of a modffled method. Journal of Immunological Methods, 11, 311-920.

Engvall, E., and Perlmann, P. (1972). Enzyme-liped immunosorbent assay, ELISA. III. Quantitation of specific 
antibodies by enzyme-labelled anti-immunoglobulin in antigen-coated tubes. Journal of Immunology, 109, 129-135. Estes, D., Atra, E., and Peltier, A. (1973). An immunofluorescent method for the detection of anti-gammaglobulin antibodies. Arthritis and Rheumatism, 16, 59-65.

Grieble, H. G., Bach, G. L., Szanto, M., and Anderson, T. O. (1969). The serologic diagnosis of rheumatoid arthritis. The latex-rabbit gamma-globulin fixation test. Journal of Chronic Diseases, 21, 667-676.

Grubb, A. (1973). Immunochemical quantitation of IgG: influences of the antiserum and of the antigenic population. Scandinavian Journal of Clinical and Laboratory Investigation, 31, 465-472.

Hay, F. C., Nineham, L. J., and Roitt, I. M. (1975). Routine assay for, the detection of IgG and IgM antiglobulins in seropositive and seronegative rheumatoid arthritis. British Medical Journal, 3, 203-204.

Hettenkofer, H. J., and Muller, W. (1975). Detection of rheumatoid factors by the indirect immunofluorescence method. Arztliche Laboralorium, 21, 174-181.

Kim, Y. T., Werblin, T. P., and Siskind, G. W. (1974). Distribution of antibody-binding affinity. III. Detection of low affinity antibody in the presence of high affinity antibody. Journal of Immunology, 112, 2002-2012.

Kotoulas, A. O., and Moroz, L. A. (1971). The detection of antibody to hemocyanin by the direct solid-phase (polystyrene) radioimmunoassay and gel filtration. Journal of Immunology, 106, 1630-1640.

Lea, D. J., and Ward, D. J. (1975). Immunoglobulin stan dards. Lancet, 1, 456.

Marcolongo, R., and Saletti, M. (1974). A modified assay for the Waaler-Rose test using latex particles coated with rabbit $\gamma$-globulins. Pathologia et Microbiologia, 40, 275280.

Nineham, L. J., Hay, F. C., and Roitt, I. M. (1976). Laboratory diagnosis of rheumatoid arthritis: a solid phase radioassay for IgG and IgM antiglobulins. Journal of Clinical Pathology, 29, 1121-1126.

Norberg, R. (1976). IgG rheumatoid factor in serum of rheumatoid arthritis patients. Scandinavian Journal of Rheumatology, 5, 124-128.

Salmon, S. E., Mackey, G., and Fudenberg, H. H. (1969). 'Sandwich' solid phase radioimmunoassay for the quantitative determination of human immunoglobulins. Journal of Immunology, 103, 129-137.

Schmidt-Gayk, H., Hufner, M., Freese, K., and Segre, G. V. (1976). Radioimmunoassay for parathyroid hormone (PTH): characterization of commercially available antigens and antisera. Fresenius' Zeitschrift fuer analvtische Chemie, Labor- und Betriebsverfahren, 279, 125. 